\title{
"VAST/O": EXPLORING
} THE USE OF EXPANDED ANIMATION FOR A \section{SHARED PHYSICAL} UNDERSTANDING

\section{OF SPATIAL PHOBIAS}

\section{NATALIE WOOLF*}

\author{
\& CAROLINA MARTINS**
}

Note: At the time of publishing, the installation is still in development, so we refer to work in progress. A preview of VAST/O as work in progress was exhibited at Bournemouth University (July 2019) and then the first complete installation took place at Atelier Concorde (November/December 2019). VAST/O future installations include a partial one at Fumetto Festival /Luzern, Switzerland (March 2020) and a full version of the work at Galeria Municipal do Banco de Portugal (Leiria, Portugal in September 2020).
* Lusófona University, Portugal natalie.woolf@network.rca.ac.uk HEI-Lab: Digital Human-Environment Interaction Lab DELLI - Design Lusófona Lisboa

** University of Coimbra, Portugal augmentedreading@gmail.com

\begin{abstract}
This paper looks at materialities of expression through expanded animation. In particular, it details the development of a creative approach for the production of artworks for an installation that will provide a shared understanding of spatial phobias and their physical and psychological symptoms.
\end{abstract}

It brings together the approach of the two authors and their individual research topics. Combining experiential phenomena of particular materials (placing animation within surfaces and technologies), and spatially distributed reading of comic book panels. The physicality of still and moving images and their distribution/placement will be explored, leading to the expansion of animation contexts.

Drawing on various makers and practices, the article explores the use of abstract comics and text as static panels and animated drawing, on-site location, and the intervention of various media technologies and other materialities to recognise their effectiveness and impact as a spatially engaged method of reading. The work developed was applied in an interdisciplinary installation titled VAST/O. The artwork is based on some theoretical approaches from literature and animation, thematically drawing on Gaston Bachelard's notion of vastness, built upon an analysis of Baudelaire's poetry, and addressing spatial phobias. It seeks to identify a way forward for the communication of the realities of phobic experiences.

Keywords: Animation, Architectonic Space, Comics, Embodiment, Materiality 


\section{Introduction}

It could be said that there are many types of materiality of expression ${ }^{1}$ found within the context of expanded animation. What you will find here is an attempt to explore some of them in order to address a creative challenge of visual communication, rather than a systematic analysis of all the possibilities.

This paper and the installation it refers to, VAST/O, began as a discussion between the two authors about how to give material expression to the communication of the realities of spatial phobic experiences. The questions were: can the material and the materialisation of the authors practices be applied in such a way as to be able to have a physical effect on the viewers body? Can they make the visitor or viewer feel, or at least understand, the body's physical reaction to agoraphobia and claustrophobia? Can the work communicate the experience of fear or anxiety that is linked to a phobia of enclosed or vast spaces, through the use of drawing, comics and animation techniques in various media?

These are conditions that Carolina Martins suffers from, so we can draw on her direct experience to identify what needs to be communicated. We have the opportunity to explore the reaction of her body in order to facilitate an understanding of these conditions to others. She has found that both phobias have similar symptoms and consequences, such as feeling both exposed and overwhelmed, and thereby causing physiological reactions, such as shortness of breath, hyperventilating, dizziness, disorientation and physical freezing of limb. They have also been well documented in medical contexts. ${ }^{2}$ The vastness of space, combined with the concept of spatial reading and the spatial phobias themselves, initially gave the installation its subject matter, and set the researchers on a quest for creative expressions of these particular psychological phenomena.

Simultaneously, the letter difference between the words vast (English) and vasto (Portuguese) became a strong visual reference for the work: For the authors, the "O" that differentiates the two words, came to symbolize a dual feeling of entrapment, be it by a claustrophobic or an agoraphobic condition, visually enclosing vastness as a boundary of inescapability and the terror of the absolute void, zero in an eternal loop.

In the exhibition space, the installation needs to be "read" as an active form of viewing, connecting the viewers directly to place and directing their movements. It will present various viewing experiences that intend to demonstrate elements of phobic physiology. At Atelier Concorde, in November 2019 (and subsequently touring) it will engage with the gallery's various spaces through a series of "set pieces" which are given these working titles: ENTRANCE, DESCENT and ARRIVAL.

On entry at Atelier Concorde, the "ENTRANCE" space presents an oddness of domesticity: Safe and familiar, and yet colourless and awkward. It will introduce the concept of mise en abyme through the presence of a live feedback loop surveilling the viewer, presented on a domestic tv screen.

The space of "DESCENT" is literal: it will take place in the stairway that leads down to the main gallery. It also performs as a distributed text that winds the viewer around the stairway, in a display of the documented thoughts and feeling of a phobic mind in crisis. We are exploring technologies that can place short animation sequences within or around this

1 In the context of the conference where this paper was presented. "In the fourth edition of Ecstatic Truth: Truth of Matter: process and perception in expanded animation practice we want to examine the potential of the animation medium, in its most expanded form, to make sense of our reality: in its encounter with matter, through all our senses." https://www.eventbrite.co.uk/e/truth-of-matter-process-and-perception-in-expanded-animation-practice-tickets-57080845345?fbclid=IWAR300REpE5tQABN6JFxWa8rJ7pf-qFSsRMXcPPqlgldmi1wH9MhRWxW7tuU\&internal_ref=login\# 
space as ways of mimicking disorientation and/or anxiety but, searching for the best way to integrate moving images into this space is technically challenging. Adding projection, screens at different scales or using handheld devices all disrupt flow of movement and therefore bring safety issues that accompany the goal of disorientation.

The final space "ARRIVAL" will present a vast drawn landscape, completing the circle around the walls of the gallery. The drawing style will be both minimal and visceral. The drawing will run from the doorway across three walls until it joins a large-scale projection of another animation, "Osseous Breath". This animation, already in development, combines sound and animated visuals that present the bodies' interior (x-ray of breathing lungs) and an allegorical expression for the fight for breath, through semi abstract paint on glass drawings. Also, within this room, there will be small animation works that can only be accessed via handheld devices. These "hidden voices", triggered by icons embedded in the visible works, allow another layer of engagement. Animated, intimate and almost secretive, gifs and short animated sequences will illustrate yet more elements of the psychological and physiological responses, thus providing a further scale change representative of the multi-layered experience of spatial phobias.

Throughout the various spaces of the gallery's structure, the "set pieces" suggest reading as enactment. Expanded comics and animations digressing from conventional panels and screens incorporate the body in space, not only as an element of that practice but also as part of the experience of spatial phobias. The bodies in space, invading both representations of intimate and public spaces, will also have a metaphorical function, in the sense that those bodies can represent the daily interactions between self and the others. Carolina found that in the context of her own phobic reactions, these interactions can result in factors of great anxiety and inability to move from one space to another ${ }^{3}$, adding additional challenges for the authors to explore.

In the following sections, it will be explained how each author understands the relation between spatial position and its psychological consequences and how they explore and transmit it through their researches and practices.

\section{Research contexts 1: material and materiality of expression}

In previous work the researchers had already explored the potential of architectonic space as a narrative agent: Carolina Martins was dealing with comic installations, in particular on mental health issues, within the growing field of Graphic Medicine ${ }^{4}$. Natalie Woolf 's PhD researched materials of change for visual and tactile communication, and her current exploration of drawing in animation practices (engendering haptic sensibility) uniting the concepts of (human) presence demonstrated through material qualities, and presence located in space.

From these different but complementary interests, they embarked on a collaboration where "linguistic meaning as grounded in bodily interaction" (Blomberg \& Thiering 2016, p. 187) could guide the development of visual expression of spatial phobic experiences. Common ground was found in thinking about how a word and an idea can join together to become a multi-layered communication. Shortly after, it was agreed that an installation would be developed to explore the

3 We use phobia suffers reported physiological reactions to spatial anxiety as reference, both Carolina's and some of the visitors' at the work in progress exhibition at Bournemouth University (July 2019)

4 BMJ 2010;340:c863 The first Comics and Medicine conference was held in London in 2010 providing a platform for both sufferers and as therapeutic approaches. For further information see the website https://www.graphicmedicine.org 
combination of theoretical thinking and creative practices to explore the elements at play.

\section{Research contexts 2: Natalie Woolf's PHD Thesis and Practice}

Recounting former research is done here to give background to the creative approach developed for the installation VAST/O. Natalie Woolf's PhD study was completed in 2004, in the Product Design Department of the Royal College of Art London, under the title "Plastic: A Material Metaphor". At its conclusion, the material plastic was presented as having a kind of otherness that suggested the possibility of virtual contact. It was proposed that the dislocation between what we can see and what we can touch was/is necessary to a bodily acceptance required for working with digital information, an idea that, at the time, was still relatively new.

In the following sections we seek to establish the link between the transference of tactile experience from a material /literal state to that of a haptic one, and then to show the creative and conceptual "products" as steppingstones to an enhanced viewer engagement: Uniting by presence - in the moment, connecting the viewer to the moving image. In conclusion, we aim to present how this became relevant to the creative process for developing the installation VAST/O

In the thesis it was argued that the invention of plastic - the first man made material ${ }^{5}$, enabled our imaginations to accept the possibility of otherness. In the first encounter with a plastic material tacit knowledge (Polanyi, 1958) of tactility, was, for a generation (that had only known natural materials) an alternative way of seeing and thinking. Physical and visual experience became disconnected and contradictory. Poetically, as Roland Barthes described, plastic is "more than a substance, plastic is the very idea of its infinite transformation [...] it is less a thing than the trace of a movement" (Barthes, 1957, p. 97-98). The term of plasticity, and by extension Eisenstein's "plasmaticness" (Eisenstein, 1986, p. 46), connects this previous thinking about materiality to the topic in hand - questioning the tangibility of visual/virtual interaction. Bringing the investigation up to date, we now seek to make the immateriality of a visual experience into a sensory one - at least haptically - if not in reality.

Research by practice: All the materials developed under the PhD study expressed various notions of plasticity: conceptually and materially and, by extension, moving and communicating.

In this article the "creative and conceptual products" discussed are animated images expressed through or within the substance of a material ${ }^{6}$. They function through spatial position. They utilize instinctive and tacit knowledge of recognizable imagery that strongly draws on common human sensibilities and moves the viewer toward an embodiment of that recognition. Also, they transfer external experiences to an integrated knowledge within internal/phenomenological spatial relationships, thereby, equating to that of Carolina Martins' approach.

In the first set of experiments, moving images were generated through the process of lenticular printing ${ }^{7}$ where a number of images can be interlaced to create the illusion of depth or

5 Made from celluloid in 1870 (and Nitrocellulose used as the first flexible film base, - enabling the first animations from around 1911) and thereafter plastics' subsequent and rapid commercialization from, for example Bakelite in 1907)

6 For the PhD the emphasis was that of plastic as communicator, the material is the message rephrasing Marshall McLuhan "The medium is the message" and, therefore, also engaging with the surrounding discussion about the concept of media. McLuhan, M. (1964) Understanding Media: The Extensions of Man, McGraw-Hill. Canada.

7 Interlacing of images dates back to the $17^{\text {th }}$ century but with the advent of plastic lenses it became readily available and even a down-market image solution for advertising and provider of images for entertainment. 

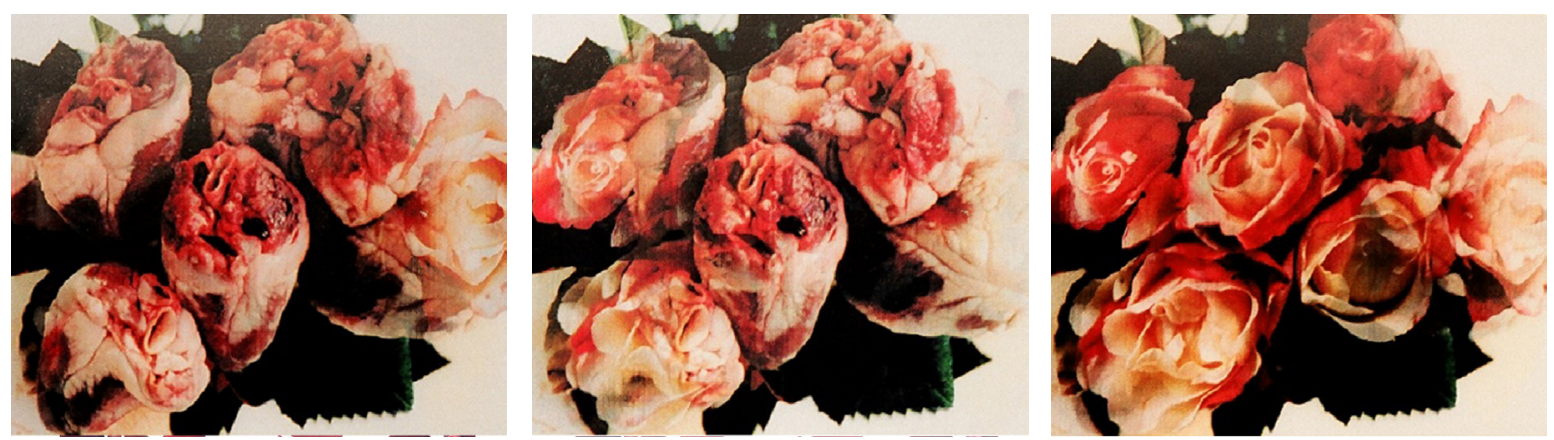

Fig. 1, 2 and 3 Hearts and Flowers Three shots of a lenticular piece that mixed two images depending on the position of the viewer. All photographs property of the artist. (2001 Natalie Woolf

animated movement. It was the process of making this piece that drew attention to the relationship between view, or "viewing angle", and the work itself. Importantly, the images are richly coloured, intending to seduce the viewer visually and then, through the movement of the viewer, to reveal the transition between images. Only through the viewers movement can the image can be played back, rewound, and explored. The image's boundaries blur into a hybrid of contradictory, and yet complimentary, shapes and colours, the lenticular lens turning the viewer into a puppet of the spectacle.

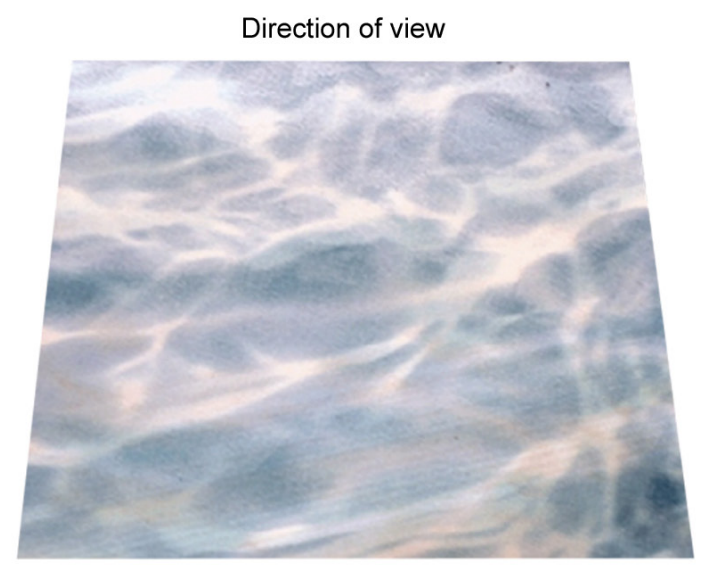

The visceral quality of these high-resolution images, both powerfully iconic, gave indication of the ability of imagery to work both through bodily knowledge - in this case attraction and repulsion - and to induce the viewer to engage in an active reading. (Fig. 1, 2 and 3 )

Having utilized lenticular images that only work on the horizontal axis, the second series of experiments (for vinyl plastic flooring) were destined to be viewed from multiple angles. Experimentation with printing techniques resulted in the

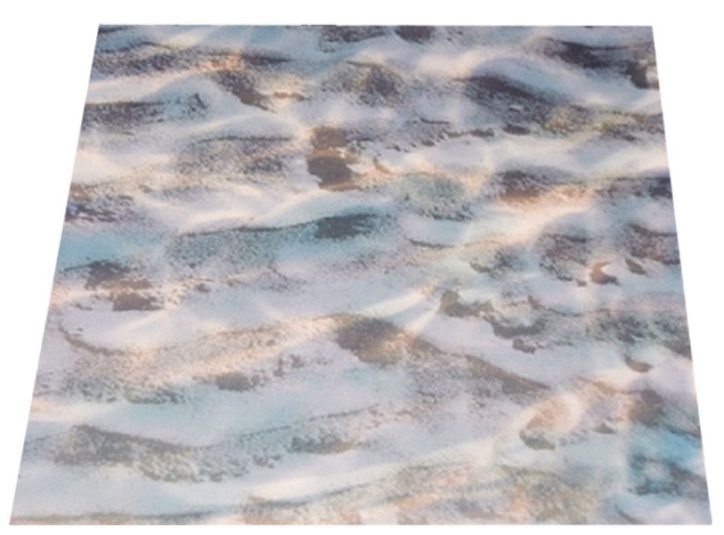

Direction of view

Fig. 4 So Moves the Sea: one individual tile photographed from two different directions revealing the two different images - the right hand view has the remains of the left hand image as it begins to disappear 
ability to produce an animated image that changed according to the angle of view, looking down on the image ${ }^{8}$, without the need for a lenticular lens. The image would dissolve from that of shallow water to the exposed and drying sand, ridged by the action of the waves. Again, both images drew on bodily knowledge of the natural world and were reproduced with a visual quality intended to highlight the memory of the physical experience: The graininess of the sand the transparency of the water for example (Fig. 4); the animation within the image emphasizing the nature of nature - in slow but constant transition.

Depending on the viewpoint you could see one or other image or various degrees of the two.

The installation, being floor based, therefore surrounding the viewer, was at full body scale, the size of a room. As you walked forward, the water appeared to flow towards you. An emersion into low-tech expanded animation. What was learnt from this, was that the imagery generated a profound physical sense of connection to the space. The view of the work was unique and belonged only to the individual - it changed only for them - reinforcing the viewers sense of presence. (Fig. 5)

This ability to achieve a heightened sense of spatially-related presence will be called upon and challenged in our endeavour to play out a claustrophobic or agoraphobic experience in the installation of VAST/O.

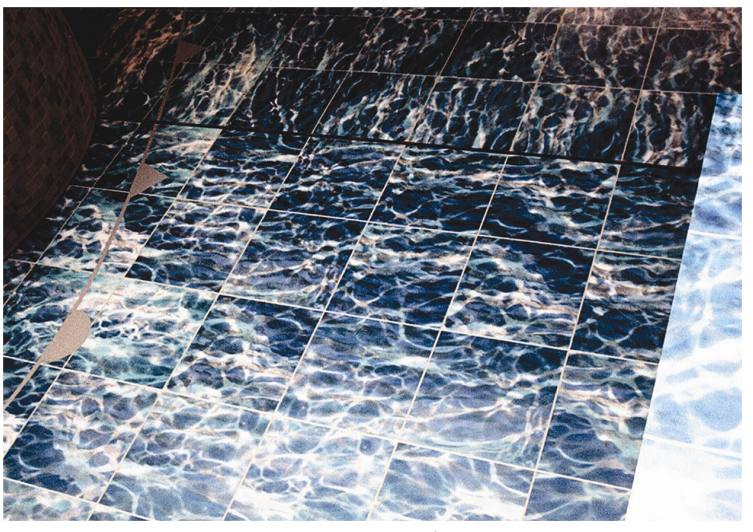

Fig. 5 So Moves the Sea

A vinyl tile installation with this moving image was made at the Russel-Cotes Museum in Bournemouth in 2000.

\section{The creative development of the installation builds on this knowledge.}

Firstly, in order to find out the most effective way to engender physical reactions, we called upon the materials from our own practices: drawing, live and animated screen-based works at different scales, projected animation, static comic book panels and the architectonic space itself.

Following up on the use of images of nature from Natalie Woolf's previous research, together with a survey of animation practice, and in particular, reference to the $\mathrm{PhD}$ research Tangible Territories (2012) by Dr. Tereza Stehlikova, it was found that there are certain visual elements that you can rely on to communicate tangible knowledge. Stehlikova specifically identifies some archetypes: water, familiar architectures, and recognizable natural environments. In order to use what Laura Marks' (2000) refers to as the tactile language of film,

8 For reasons more fully detailed in the PhD tesis

9 The "theory that haptic visually gives rise to embodied sense memory" Marks, Laura U. "Research: Haptic Visuality." Laura U. Marks, Simon Fraser University, www.sfu.ca/ Imarks/styled-7/ (last accessed 05.02.2020). 

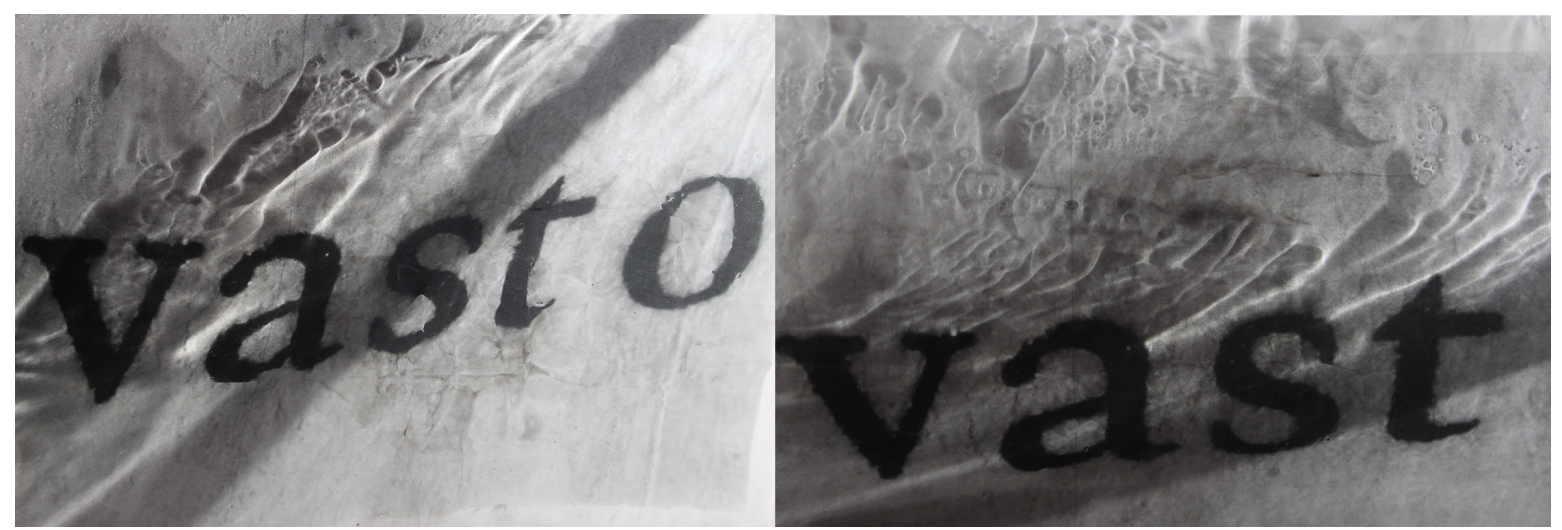

Fig. 6 Test images combining text and water effects

we selected both water and the body as our starting points for experiments to evoke physical memories. (Fig. 6)

At first, we represented visually the kind of breathing that can be experienced during a panic attack. We experimented with a combination of animated drawn images and the transparency and intimacy of chest $x$-rays films. In this we found what Lilly Husbands and Caroline Ruddell, writing on Eisenstein's fascination with Disney, describe as animation's "ability to evoke certain synaesthetic, empathetic, and ecstatic sensations through watching images move in time" (Dobson, Honess Roe, Ratelle, \& Ruddell, 2018, p. 13). As we watched the first tests, we felt our bodily knowledge called up by the visual sequences. In subsequent exhibitions we hope to be able to use similar techniques to share or show some of the other physical symptoms of an anxiety attack.

Through this experimental testing, key aspects of particular animation techniques, like paint on glass, were found to be effective. By combining touch as visual memory, heightened through the physicality of paint on glass's ability to capture gesture, we believe that this technique conveys haptic sensory perception. Many exist, but a convenient example of this is the very short scene from "The Street", by Caroline Leaf, where the mother is brushing the daughter's hair. Arguably, this sequence delivers a visceral experience of the action through the movement of the drawn line. Similar to this, in these tests for VAST/O, the drawn line gives tangibility to the friction of (difficult) breathing. (Fig. 7, 8, 9 \& 10)

Further research on representation of the human body led us to consider using the visual elements that can be linked most closely to the notion of mimesis ${ }^{10}$ A typical example would be when presented with images of yawning, breathing (as in " breathe in"), and in instructions to "open wide" your mouth, (for example, at the dentist), the viewer cannot resist "performing" likewise. We found this phenomenon clearly demonstrated in the installation BREATHE by Dryden Good$w^{11}$. In spite of the circumstances of its commission (the issue of urban air quality's impact on health), we find ourselves breathing in tandem when watching the piece.

Finally, when we focused on the phonetic differences between the words Vasto and Vast, and the state of breathlessness

10 As identified in Laura Mark's Touch: Sensuous Theory and Multisensory Media 2002 p115. "the gleam of the knife edge in G. W. Pabst's Lulu makes you flinch" Deleuze, Gilles Cinema 1: The Movement-Image trans Hugh Tomlinson and Barbara Habberjam (University of Minnesota Press 1987), 97.

11 BREATHE (2012) Dryden Goodwin (https://www.drydengoodwin.com) 


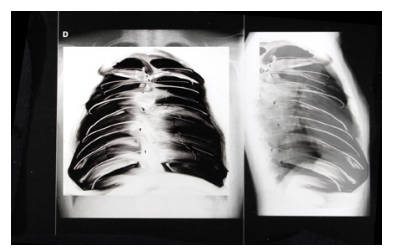

Fig. 7, 8, 9 and 10 Test images combining $x$-ray film and

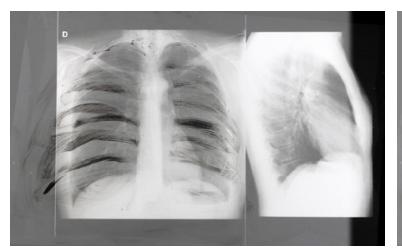
caused by the utterance of the English word, the decision to use of animation to encourage emotional reaction became even clearer.

Testing visual and audio together allowed us to understand sound was an extremely important element and that, by going beyond just "showing" breathing, we could expand the animation itself and, with it, the space where it was being projected.

\section{Research contexts 3: \\ Carolina Martins' research and practice}

Carolina Martins' thesis, "Augmented Reading ${ }^{12}$ : spatial combinations in graphic narratives installations", proposes an analysis of the potential of architectonic space as a narrative agent, as well as an analysis of the possibilities of interaction between different types of spaces for the development of the narrative. It is a reflection on the possibilities and ways of extending the page and about a narration made possible by the loop generated by the inter-relation between the architectural space, the narrative, and the reader.

Because of its particular use of page space, point of view and one-page comics panels, Martin Vaughn-James' book The Cage (2013[1975]) was a starting point for Carolina's research and practice. This book's intentional disconnection between text and image, by means of juxtaposing opposed senses and representations, can make us feel both confused and closer to the reading at the same time. These are the paradoxes we would like to capture in VAST/O, which aims to
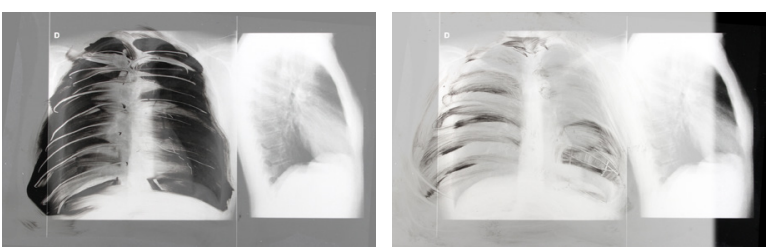

be a piece that generates the sensations of paradoxical spatial experiences by combining actual and animated spaces. The paradox will be reinforced by the subject of apparently opposed spatial anxieties, like agoraphobia and claustrophobia. Namely, by asking how they can co-exist and how people experience them. Thus, through the use of comics and animation in space, be it through traditional or other channels, we hope to provide meaningful layers that enhance the reader's engagement with the piece.

Warren and Gary Pleece's Montague Terrace present a "set" where the visitor enters an apartment and can-select animations that show the neighbours' daily life. In Marc-Antoine Mathieu's SENS. The fluidity of animation and its light are used to dictate the pace of reading through a unicursal labyrinth. Both examples show different places where the visitor can relate to the narrative, each one conveying a different type of space: the domestic and the outdoors. What we aim for the structure of VAST/O is a setting where those spaces can co-exist and how both of them can substantiate both security and fear.

Marietta Ren's digital comic Phallaina, in which the reading is made by scrolling through the screen, also contributed to the planning of VAST/O. It conducts the reader through the thoughts and interior images of someone suffering from a neurological disease. This reading form proposes a kind of (or expanded) animation on its own and gives us a sense of space even if just through (handheld) screens, by incorporating gesture. Together with SENS VR, a Virtual Reality game

12 Departing from the term and concept of "Augmented Space", coined by Lev Manovich (2006) 
for Mathieu's book, these digital works are relevant examples to deal with when it comes to comics and animation relationships and how can they induce certain feelings and actions in the reader. Also, they contribute to the questioning of the uses of apps for reading comics or to be used in the real, architectonic space.

Continuing the research analysis, Jacques Derrida's notion of the crypt led Carolina to the question - "what is an exhibition space if not a crypt?". She reflects on the potential and the capacity of the exhibition space to hold and reconfigure a text and it's reading. Proposing that it becomes a chamber where interior and exterior are not distinct but co-extensible. This view also reflects the gallery's capacity for being altered by the installation structure, as Brian O'Doherty acknowledges in Inside the White cube (1986), promoting the "effect of the container on the contained" (69). Hence, "the evolution of the gallery from being a container that displays works of art to a chamber that can become an immersive landscape (...)" (Martins, 198).

Adding to this, the recognition that art found a "[...] mode of locating the boundary where person ends and something begins" (O'Doherty, 78), leads us to say that VAST/O attempts to blur those boundaries through the intertwining of comics and animation in their expanded forms. And, from this expanded environment, a certain reality is shaped for the audience to feel incorporated in the narrative, corrupting one of the key elements of comics: the gutter.

In comics, the gutter is a kind of "venue where the minds of readers interact with the comics text' (Kukkonen, 216), stating what belongs in the realm of the fictional or of the real world. Thus, in the context of an installation, where those boundaries are not so clear, the reader is constantly in and out of the gutter, traversing real and fictional ${ }^{13}$.
In these examples, the gutter is diluted in a hybrid space, becoming a venue to be traversed and used as a connection. In the case of installations, this space becomes a literal venue bordered object by object where the readers are juxtaposed in praesentia (cf. Groensteen, 148).

\section{Combining theory and practice: installation and collaborations}

The aesthetics we want to use for the installations' comics panels is an abstract one, combining gestural mark making with written poetry. It is predicted to begin at the ENTRANCE and continue throughout. We decided to introduce an abstract style by João Carola, with whom Carolina conceived a first visual poem entitled Like Glass related with the theme of anxiety. Using this style will allow exploration throughout the space, enhancing the route of the text, removing the distraction of boundaries. This option will grant freedom in the sense that people do not have to focus on too much information at once. A non-figurative style of drawing seems a good fit to enhance the role of expanded animation and, therefore, contributes to an immersive environment.

In fact, the ENTRANCE is the "set" that is expected to be central in VAST/O, representing not mere immobility, but above all the universe contained in a personal space. The screen monitor at its heart becomes a representation of withdrawal from the outside world, while replacing it with unreal images, turning the monitor into an "extension of the being", something we explore as a reading of the relation between the domestic space and the outside world(s).

While conversing with Barbara Nierhoff (2003, p. 214), artist Peter Campus said: "When I was young I made myself a prisoner of my own room. It became ... an extension of my being. ... The room as a container had some relationship to the imaginary space inside a monitor." This concept and the

13 As Carolina explained elsewhere - See Martins, 2019, 204 
space of ENTRANCE is not far from Bachelard's belief of the inner space as immense, which he praised also by referring to vast as "a word that ... opens up unlimited space" and a "vowel of immensity".

Identifying the word "vast" in Bachelard's (1958) analysis of the word, built upon Baudelaire's work, in the book The Poetics of Space (originally in French) introduced the set of literary concepts that expanded our initial ideas.

In particular, it was Baudelaire's quote "The word vast reconciles the contraries" (2003, p. 209) that called to attention the differences between the sounds of the word in different languages, as previously referred to in this article.

For instance, 1) the French word "vaste", from the original text, is pronounced with the same soft " $A$ " of many English regional accents; 2) in English received pronunciation "vast" has a hard "A"; and 3) the equivalent Portuguese word "vasto" ends with an unstressed $O$ sound - closed, phonetically as well as physically, drawing in the face or mouth.

This wordplay returned us to the physicality of speech, the vocalization of the word in all 3 languages also resulting in a certain element of breathlessness. To put vastness into a form of visual representation that draws out, not just the notion of awe and wonder usually associated with the utterance of the term. In vocalizing it, one expresses a word that fills space and the "mind's eye", but empties the speaker: You can feel the compression of the lungs as the word is spoken - "it makes you use all your air until you are left with none"14.

Because neither of the authors are fluent in French, they selected to only work exploring both their mother tongues. Thus, only working with the English and Portuguese variations of the word also gave license to play with the single letter difference. Conveniently, the letter being an "O" offered numerous symbolic meanings and representations. For example "circumference" in that "[B]odily space can be distinguished from external space and envelop its parts instead of spreading them out," (Merleau-Ponty, 2005, p. 115), thereby delineating interior from the exterior, the latter being intrinsic to notions of self and the two phobias to be addressed. This, we intend to expresse as a circular drawing in the ARRIVAL space. Closing the loop of the $\mathrm{O}$ and wrapping the viewer in a vast continuous gesture drawing.

\section{Conclusion}

In this inter-artistic installation, the role of animation is essential to consolidate the piece. It proposes an augmented space whose aim is to illustrate and/or demonstrate phobic and/or anxious feelings to the audience. Firstly, animation will be used to expand the installation space within its physical confines and, ultimately, it will be used through the apps to extend the installation beyond the installation walls into real personal space.

The tests are ongoing, in different media and of different visual imagery. There are still many possible creative solutions to be explored. However, as discussed in the contexts and case studies, theory and practice have combined to present a number of ways forward. We have documented how the theory has influenced, sometimes in advance of, and sometimes in support of the practical approaches. Our tests have produced some of the spatially rooted and haptic results we hoped for through various materialities of expression: Such as allegorical gesture drawing for the fight for breath - realised through a paint on glass technique. And we have recognized the need for more solutions and other ways of inducing feeling of entrapment, which will be worked on in the near future.

14 Quote from the discussion 
The continuation of this practical research is also guiding us towards the selection of different media and scale for the various elements and themes.

We are still developing how these various visual elements should surround and immerse the viewer, how they respond to each gallery, where they should be more integrated into the set pieces and when they are most effective as the hidden elements only revealed through an imitate reading within some of the other spaces. For example, the possibility to watch through a monitor, inside or outside the gallery, resonates with Peter Campus' view (as stated above) of a relation between an intimate room and the experience of watching something through a monitor. Hence the importance to continue to investigate the impact of other media technologies, that will either intervene and be further distancing, or provide an additional level of focus and information. We also consider places outside the installation, before or after the installations' existence, in a particular time and space. This can be achieved through a combination of online presence, paper booklet and an app for handheld devices to stream moving images.

We have learnt of the importance to this subject of the breaking down of various elements -not to bombard and overwhelm, as this may result in an unmanageable immersion into spatial phobia. Feedback from the work in progress exhibition has already proved some of the communication methods are interpreting the symptoms well and have assisted in communicating some of the physiological reactions. We have recognized the difference between the communication of phobic elements and the inducement of phobic reaction. We developed a spatial distribution that will allow for a step by step process of engagement. The visitor will pass through the texts - instituting a slower reading and the set pieces demonstrating individual scenarios. We will use technologies of surveillance and explore the materialities of expanded animation to highlight and focus on some of the more anxious and visceral elements of the installations themes.
Intentionally, the installation presents both a closed space (ENTRANCE), apparently stable, but also claustrophobic and unbreathable; and an open space (ARRIVAL), vertiginous and agoraphobic. In Research Context 1, the paradox of special phobias and its relationship to our approach for VAST/O using still and moving image, was argued. The combination of media providing the shifting sands of instability.

VAST/O aims to respond through various media, to the presence and movements of people and vice-versa. Such a relationship with the viewer/reader also invokes inter-spatial relationships in itself.

Referring to the role of the gutter in comic book reading and how it extends in an installation context, we propose that the dilution of the gutter can also be viewed as a celebration of what Norman McLaren refers to in his definition of animation. The viewer is placed in "the gutter between panels" and therefore also "the space between frames", where their movements determine the experience of the works: in this case, by extension, the installation space where expanded animation occurs. Where the viewer/reader and the works intermingle at the site of engagement, (architectonic space) enabling the ecstatic truth of spatial phobias to be revealed. 


\section{References}

Bachelard, Gaston (1958). The Poetics of Space.

Barthes, Roland (1957). Mythologies. p97-98

Blomberg, Johan \& Thiering, Martin (2016). Spatial phenomenology and cognitive linguistics: the case of bodily and perceptual spaces. Metodo. International Studies in Phenomenology and Philosophy, 4, 159-212, doi: 10.19079/metodo.4.2.159.

Caplescu, Oana Andreea (2013). "Augmented Spaces, A Look Beyond Advertising". Urbanism. Architectura. Constructii, Vol. 4 (3).

Dobson, Nichola; Honess Roe Annabelle; Ratelle Amy. Ruddell Caroline (Eds) (2018). The Animation Studies Reader.

Approaching Animation and Animation Studies Heidegger, M. (1996). Being and Time. trans. J. Stambaugh, Albany, State University of New York Press.

Kukkonen, Karin (2011). 'Metalepsis in popular culture', in K. Kukkonen and S. Klimek (eds), Metalepsis in Popular Culture, Berlin: de Gruyter, pp. 1-21.

Groensteen, Thierry (2007). The System of Comics. Jackson: University Press of Mississippi.

Manovich, Lev. (2006). 'The poetics of the augmented space', Visual Communication, Vol. 5(2), pp. 219-40.

Marks, Laura (2000). The Skin of the Film: Intercultural Cinema, Embodiment, and the Senses.

Marks, Laura (2002) Touch: Sensuous Theory and Multisensory Media.

Martins, C. (2018). 'Unfolding and crossing the augmented space: Metaleptic tools and processes within graphic narrative installations', Studies in Comics, 9:2, pp. 193-207, doi: 10.1386/stic.9.2.193_1.

Mathieu, Marc-Antoine (2014). S.E.N.S. Paris: Delcourt.Merleau-Ponty, Maurice (2002) [1962] :115) Phenomenology of Perception.

Merleau-Ponty, Maurice. (2002[1962]) Phenomenology of Perception.

Nierhoff, Barbara (2003). "Conversation with Peter Campus. The Eternity is in the Moment", Peter Campus: Analog + Digital Video + Foto 1970-2003, Kunsthalle Bremen, Bremen, Germany.

O'Doherty, Brian (1986). Inside the White Cube: The Ideology of the Gallery Space, San Francisco: The Lapis Press.

Pine II, B \& H Gilmore, J. (2013). The experience economy: past, present and future. doi: 10.4337/9781781004227.00007.

Pleece, Gary and Warren (2013). The Montague Terrace. London: Vintage Publishing.

Polanyi, Michael (1958). Personal Knowledge Towards a Post-Critical Philosophy.

Ren, Marietta (2016). Phallaina. Smallbang and France télévisions Nouvelles écritures.

Sullivan, Graeme. (2005 \& $2^{\text {nd }}$ Edition 2010). Art Practice as Research Inquiry in the Visual Arts.

Vauggn-James, Martin (2013[1975]). The Cage. Toronto: Coach House Books.

Woolf, Natalie. (2004). 'Plastic: A Material Metaphor: a Conceptual and Practical Investigation of Plastic Qualities as Material and as Metaphor' (Unpublished doctoral dissertation). Royal College of Art, London. 